\title{
Formação Inicial de Professores de Biologia: Uma Proposta de Sequência Didática sobre a Natureza da Ciência
}

\author{
Adalberon Moreira de Lima Filho' ${ }^{\text {; Maria Delourdes MacieF }}$ \\ 凹alberon.filho@ifal.edu.br
}

1. Instituto Federal de Educação, Ciência e Tecnologia de Alagoas.

2. Universidade Cruzeiro do Sul - UNICSUL - São Paulo - Brasil.

\begin{abstract}
Histórico do Artigo: 0 autor detém os direitos autorais deste artigo.
Recebido em: 03 de junho de 2020 Aceito em: 13 de janeiro de $2021 \quad$ Publicado em: 31 de agosto de 2021
\end{abstract}

\begin{abstract}
Resumo: Em geral, as visões sobre Natureza da Ciência são deformadas e distorcidas devido a um modelo de ensino tradicional baseado, sobretudo, na transmissão de conhecimentos conceituais. Diante disso, objetivou-se elaborar e aplicar uma Sequência Didática a respeito da Natureza da Ciência destinada à formação inicial de professores de Ciências Biológicas. A pesquisa é de caráter qualitativo do tipo intervenção. Participaram dela 11 estudantes do curso de Ciências Biológicas - Licenciatura. A Sequência Didática foi estruturada em: problematização inicial, organização e aplicação do conhecimento. Os instrumentos utilizados para a coleta de dados foram textos produzidos pelos alunos e observações de sala de aula. Os dados foram submetidos à técnica de análise de conteúdo. Os resultados obtidos revelaram que as atividades propostas na Sequência Didática foram adequadas, já que os alunos conseguiram compreender suas concepções prévias sobre Ciência, aspecto que proporcionou condições favoráveis para a promoção de uma mudança conceitual dos futuros professores. Além disso, evidenciamos que os participantes, com auxílio dos materiais disponibilizados, foram capazes de analisar as falas de outros docentes e identificar suas visões de Ciência. A aplicação da Sequência Didática possibilitou aos participantes uma maior abrangência da compreensão das visões distorcidas da Ciência e de suas implicações para 0 ensino. Ademais, atividades propostas durante a aplicação contribuíram para a tomada de consciência pelos futuros professores das complexas relações entre a Ciência, sociedade e tecnologia.
\end{abstract}

Palavras-chave: Natureza da Ciência, Sequência Didática, Formação Docente, Ciências Biológicas.

\section{Initial Formation of Biology Teachers: A Didactic Sequence Proposal on Nature of Science}

\begin{abstract}
The views on the Nature of Science, in general, are distorted and distorted due to a traditional teaching model-based, above all, on the transmission of conceptual knowledge. Therefore, the objective was to develop a Didactic Sequence on Nature of Science for the initial training of Biological Sciences teachers. The research is a qualitative intervention type. Eleven students from the Biological Sciences course - Licenciatura participated. The Didactic Sequence was structured in: initial problematization, organization and application of knowledge. The instruments used for data collection were texts produced by students and classroom observations. The data were submitted to the content analysis technique. The results obtained revealed that the activities proposed in the Didactic Sequence were adequate, since the students were able to understand their previous conceptions about Science, an aspect that provided favorable conditions for the promotion of a conceptual change of future teachers. In addition, we showed that the participants, with the help of the materials made available were able to analyze the speeches of other teachers and identify their views on Science. The application of the Didactic Sequence enabled the participants to have a wider range of understanding of the distorted views of Science and its implications for teaching. Also, activities proposed during the application contributed to the awareness of future teachers of the complex relations between Science, society and technology.

Keywords: Nature of Science, Didactic Sequence, Teacher Education, Biological Sciences.
\end{abstract}




\section{Formación Inicial de Profesores de Biología: Una Propuesta para Enseñar la Secuencia sobre la Naturaleza de la Ciencia}

Resumen: Las opiniones sobre la Naturaleza de la Ciencia, en general, están deformadas y distorsionadas debido a un modelo de enseñanza tradicional basado, sobre todo, en la transmisión del conocimiento conceptual. Frente a eso, el objetivo fue elaborar y aplicar una Secuencia Didáctica sobre la Naturaleza de la Ciencia destinada a la formación inicial de los profesores de Ciencias Biológicas. La investigación es de carácter cualitativo de tipo intervención. De ella participaron 11 estudiantes del curso de Ciencias Biológicas - Licenciatura. La Secuencia Didáctica fue estructurada en: problemática inicial, organización y aplicación del conocimiento. Los instrumentos utilizados para la recolección de datos fueron textos producidos por estudiantes y observaciones en sala de aula. Los datos fueron sometidos a técnica de análisis de contenido. Los resultados obtenidos revelaron que las actividades propuestas en la Secuencia Didáctica fueron adecuadas, ya que los estudiantes pudieron comprender sus concepciones previas sobre la Ciencia, un aspecto que proporcionó condiciones favorables para la promoción de un cambio conceptual de los futuros profesores. Además de lo mencionado, mostramos que los participantes, con la ayuda de los materiales disponibles, fueron capaces de analizar los discursos de otros docentes e identificar sus visiones sobre la Ciencia. La aplicación de la Secuencia Didáctica permitió a los participantes tener una mayor comprensión sobre las visiones distorsionadas de la Ciencia y sus implicaciones para la enseñanza. Además, las actividades propuestas durante la aplicación contribuyeron a la toma de conciencia por los futuros profesores de las complejas relaciones entre ciencia, sociedad y tecnología.

Palabras clave: Naturaleza de la Ciencia, Secuencia Didáctica, Formación Docente, Ciencias Biológicas.

\section{INTRODUÇ̃̃o}

0 desenvolvimento profissional dos docentes é objetivo de qualquer proposta educacional que valorize a sua formação não mais baseada na racionalidade técnica que considera os professores meros executores de decisões prontas, mas numa nova formação de professores de Ciências que atuarão na Educação Básica, fundamentada na necessidade do domínio de teorias científicas e das suas relações com a tecnologia e a sociedade (Delizoicov; Angotti; Pernambuco, 2011).

0 aprendizado da Ciência tem que permitir que os alunos dos diferentes níveis de escolaridade entendam o funcionamento da Ciência e da comunidade científica, para saber como o conhecimento científico é construído e validado, de modo que desenvolvam uma consciência dos valores envolvidos nas atividades científicas (Ros, 2012).

Para que o ensino amplie a compreensão dos alunos sobre Ciência é fundamental que os professores orientem esse conhecimento, realizando perguntas estimuladoras e usando a argumentação como ferramenta para um ensino criativo. Entretanto, as concepções de Ciência que vários docentes possuem estão recheadas de equívocos sobre o conhecimento científico (CACHAPUZ et al., 2011; DUBARNO, 2015).

Sendo assim, constitui-se como prioridade a ampliação das bases epistemológicas na formação de professores para um entendimento aprofundado da educação científica. 
Formação Inicial de Professores de Biologia: Uma Proposta de Sequência Didática sobre a Natureza da Ciência

Entendimento este que proporciona condições de um ensino que enculture cientificamente os estudantes (CARVALH0, 2013).

Contudo, o modelo de ensino tradicional persiste com a formação docente focada, sobretudo, na transmissão de conhecimentos conceituais. Outro aspecto que consideramos é a escassez nos currículos da formação inicial de professores de Ciência e Biologia, das abordagens históricas e filosóficas da Ciência. Estes aspectos criam dificuldades para os futuros professores detectarem quais as características sobre a construção do conhecimento científico que seriam úteis para auxiliar na promoção de um ensino de Ciências mais contextualizado.

\section{Natureza da Ciência}

Ao longo do tempo surgiram várias definições e compreensões sobre a Natureza da Ciência. Assim, no final do século XIX, o conceito de Ciência estava relacionado ao método científico (MC). Deste modo, em 1960 a Ciência era conceituada pela lógica das etapas do MC, sendo que a definição está relacionada à lógica das seguintes etapas: observação, hipótese, inferência, interpretação de dados e experimentação. Na década seguinte do mesmo século era compreendida como conhecimento provisório, histórico e humanístico. Essa nova definição ocorreu devido à obra de Khun (DURBANO, 2015).

Na década de 80, a Psicologia e a Sociologia contribuíram para uma nova definição de Ciência, e fatores como a teoria da observação, a criatividade humana e a estrutura social das organizações científicas englobavam esse novo conceito. Nos anos 1990, os pesquisadores do departamento de Educação da Califórnia definiram Ciência como atividades científicas, as quais seriam orientadas por teorias e os cientistas realizariam suas investigações (DURBAN0, 2015).

Assim, ao longo de décadas, este conjunto de elementos que tratam da construção dos diferentes conceitos da Ciência e da organização do conhecimento científico que abrangem as questões sociais, culturais, religiosas e políticas é o construto denominado Natureza da Ciência (NdC), que tem sido usado para referir-se não a Ciência em sentido mais amplo, mas sim, aos aspectos do conhecimento científico e a forma pela qual ele é produzido ao longo do tempo (GROTZER, MILLER, LINCOLN, 2012; MOURA, 2014; DURBANO, 2015).

Nesta mesma linha de pensamento Vásquez-Alonso et al. (2007); Sánchez e Gómez (2013), compreendem que a $\mathrm{NdC}$ engloba uma variedade de aspectos sobre o que é a Ciência. Seu funcionamento interno e externo, a construção e desenvolvimento do conhecimento científico, os métodos que usa para validar esse conhecimento, os valores envolvidos nas atividades 
científicas, a natureza da comunidade científica, os vínculos com a tecnologia, as relações da sociedade com o sistema tecno-científico e vice-versa, as contribuições desta para a cultura e o progresso da sociedade.

Contudo, há aspectos que constituem visões consensuais entre pesquisadores: 0 primeiro é reconhecer que a Ciência é mutável, dinâmica, e objetiva explicar os fenômenos naturais; segundo, é o reconhecimento de que não existe um método científico universal; terceiro, a teoria não é consequência das observações ou experimentos e vice-versa; quarto, que há influência do contexto social, cultural e político sobre a Ciência; e o quinto aspecto é que para fazer Ciência os cientistas utilizam suas crenças, influências externas e são seres humanos com qualidades e defeitos. Assim como não há um método universal para fazer Ciência, não existe um cientista padrão (MOURA, 2014).

Para Cachapuz et al. (2011), o problema é que a Natureza da Ciência surge distorcida na educação científica, inclusive na universidade. Então, é necessário superar as visões deformadas e empobrecidas da Ciência e Tecnologia (CẼT), que são aceitas socialmente. 0 autor e seus colaboradores apontam as seguintes visões deformadas:

A primeira: descontextualização e a neutralidade das atividades científicas e tecnológicas. Há um esquecimento de que essas atividades têm impactos no meio natural e ambiental, que são de interesses ou influências da sociedade no seu desenvolvimento. Em geral, as pessoas ignoram ou tem dificuldades de estabelecer as conexões entre Ciência - Tecnologia - Sociedade (CTS), bem como, Ciência - Tecnologia - Sociedade - Ambiente (CTSA) (CACHAPUZ et al., 2011).

A segunda: considerar que o trabalho científico é um domínio reservado às minorias, especialmente dotadas deste elitismo, que é uma concepção dominante, contempla a Ciência como uma atividade de gênios isolados, como também há claras discriminações de natureza social e sexual. Dessa forma, a imagem individualista e elitista do cientista traduz-se em iconografias que apresentam o homem de bata branca em seu inacessível laboratório, repleto de estranhos instrumentos (CACHAPUZ et al., 2011).

A terceira: também é uma visão deformada que está na concepção empírico-indutivista e ateórica. Nesta, há a defesa do papel da observação e da experimentação não contaminadas por ideias aprioristas; as hipóteses são esquecidas como focalizadoras da investigação e dos corpos coerentes de conhecimentos disponíveis, que orientam o processo (CACHAPUZ et al., 2011).

A visão infalível neste método científico é tratada como uma sequência de etapas definidas, em que as observações e as experiências rigorosas desempenham um papel destacado 
Formação Inicial de Professores de Biologia: Uma Proposta de Sequência Didática sobre a Natureza da Ciência

que contribuem para a exatidão e objetividade dos resultados obtidos, assim como a concepção empírico-indutivista apoia-se na ideia de que o conhecimento científico está finalizado em uma simples aplicação de método científico. Consequentemente, a atividade científica é a problemática e a-histórico, já que nesta concepção são frequentemente ignorados quais foram os problemas que se pretendiam resolver, como ocorreu a evolução dos conhecimentos científicos e as possíveis dificuldades encontradas (CACHAPUZ et al., 2011).

Outra deformidade é ter a concepção que a Ciência é exclusivamente analítica. Pois desse modo, considera-se que a atividade científica ocorre pela divisão de estudos, limitação e simplificação do processo. Essa visão é particularmente grave, já que muitos a aceitam com mais facilidade, principalmente entre os professores.

Assim como considera-se que os conhecimentos científicos são acumulativos e frutos de um crescimento linear, aqueles que enxergam a Ciência dessa forma ignoram as crises e as remodelações profundas, fruto de processos complexos que não se deixam ajustar por nenhum modelo definido de desenvolvimento científico (CACHAPUZ et al., 2011).

É fundamental que os docentes entendem a arquitetura da elaboração do conhecimento científico, principalmente, os professores de Ciências que são os mediadores do processo ensinoaprendizagem das Ciências, além disso, são os aqueles que conduzem as primeiras reflexões e ensinamentos das questões científicas.

\section{Ensino de Ciências}

0 ensino de Ciências no Brasil tem sido tradicionalmente livresco e descontextualizado, levando os discentes a decorar conteúdos, sem compreender as suas aplicabilidades e conceitos. Assim, as Ciências experimentais são desenvolvidas sem relação com a realidade. Como resultado, a maioria dos alunos considera que é difícil aprender Ciências e, consequentemente, perdem o entusiasmo por elas. Além disso, a escola não está preparada para promover um ambiente que favoreça a educação científica e tecnológica (UNESCO, 2005).

Teixeira (2003) avalia o ensino de Ciências e seus componentes curriculares de Biologia, Química, Física e Matemática. É notável que o perfil de trabalho de sala de aula nesses componentes esteja rigorosamente marcado pelo conteudismo, exigência excessiva de memorização de algoritmos e terminologias, descontextualização e ausência de articulação com as demais disciplinas do currículo. 
Para Delizoicov; Angotti; Pernambuco (2011) há vários desafios para o ensino de Ciências que devem ser enfrentados, entre eles:

1. Superação do senso comum pedagógico: os professores precisam ter o domínio de teorias científicas e de suas vinculações com as tecnologias.

2. Ciência para todos: o saber científico ao alcance de todos os segmentos sociais e com maioria expressiva oriunda das classes e culturas que não frequentam a escola.

3. Ciência e tecnologia como cultura: a ação docente deveria buscar construir o entendimento de que o processo de produção do conhecimento constitui uma atividade humana, sócio-histórica e submetida a pressões internas e externas.

4. Incorporações de conhecimentos contemporâneos dos resultados científicos e tecnológicos permeiam a vida cotidiana de maneira sem precedentes. Então, o desafio é incorporar a prática docente aos programas de ensino de Ciência e Tecnologia relevantes para a formação cultural dos discentes.

5. Superação das insuficiências do livro didático: o livro didático ainda é o elemento predominante, o principal instrumento de trabalho e a principal referência dos docentes nas salas de aula. Portanto, são necessários novos recursos para superação dessa velha prática pedagógica, ou seja, inserir metodologias que conduzam os estudantes ao protagonismo.

6. Aproximação entre pesquisa em ensino de Ciências e Ensino de Ciências: a apropriação, a reconstrução e o debate sistemático dos resultados de pesquisa na sala de aula e na prática docente dos professores dos três níveis são sofríveis.

Desde o primeiro momento, essas investigações baseiam-se em duas hipóteses implícitas (Lederman, 1992):

1. A compreensão dos professores acerca da NdC tem uma certa relação com a dos seus alunos e com a imagem que estes adquirem da Ciência.

2. As crenças dos professores sobre a NdC influenciam significativamente a sua forma de ensinar Ciências e as decisões que tomam na aula.

Diante do exposto pelos autores, podemos perceber que as concepções dos professores sobre a construção da ciência, refletem diretamente nas metodologias adotadas por eles para ensinar Ciências. Por isso, esses precisam ser preparados para entender como a Ciência construída e as influências afetam o seu desenvolvimento. 
Formação Inicial de Professores de Biologia: Uma Proposta de Sequência Didática sobre a Natureza da Ciência

Nesse contexto, emergiu a questão (problema) desta pesquisa: como elaborar atividades para os cursos de formação de professores que contribuam para o entendimento e identificação das visões equivocadas da Ciência? Tomando como base este questionamento, objetivou-se de modo geral: facilitar a compreensão dos futuros professores de Ciências Biológicas sobre aspectos da $\mathrm{NdC}$ que deveriam ser evitados quando ensinados, desse modo, para alcançar este objetivo elaboramos uma Sequência Didática (SD) sobre NdC, contendo situações problemas que abordassem as concepções equivocadas sobre o conhecimento científico.

Este artigo está organizado da seguinte maneira: após essa introdução, a seção 2 apresenta a metodologia; a seção 3 os resultados e discussão; e a seção 4 as considerações finais.

\section{METODOLOGIA}

A pesquisa está pautada pelo modelo qualitativo do tipo intervenção, que, segundo Chizzotti (2018), caracteriza-se pela relação dinâmica entre o mundo real e o sujeito, o sujeito e o objeto, o mundo do objeto e a subjetividade do sujeito. Nesta perspectiva, o pesquisador é o sujeito-observador, e é parte integrante do processo de conhecimento, pois interpreta os fenômenos atribuindo-lhes um significado, além de identificar as teorias em uso e debatê-las para posteriormente avaliar os efeitos das mudanças nos sujeitos.

A pesquisa qualitativa do tipo intervenção possibilita compreender melhor o tema investigado, pois permite que o pesquisador identifique e compreenda as concepções, as representações, as opiniões, as emoções e os sentimentos dos estudantes. Outra vantagem da pesquisa de intervenção, segundo o mesmo autor, é permitir ao pesquisador intervir de forma consciente sobre o tema abordado durante o desenvolvimento da pesquisa, modificando e acompanhando situações.

0 estudo foi realizado em uma instituição pública brasileira, localizada na região Nordeste do Brasil. A aplicação da Sequência Didática ocorreu no mês de novembro de 2017 e todos os 11 (onze) participantes assinaram Termo de Consentimento Livre e Esclarecido (TCLE). Os instrumentos de coleta de informações sobre a SD e posteriores análises foram os registros escritos (diário de campo) do pesquisador e as atividades manuscritas produzidas pelos alunos participantes.

\section{Fundamentos e Estrutura da Sequência Didática (SD)}


A Sequência Didática sobre Natureza da Ciência destinada para formação inicial de professores foi formatada de acordo com os elementos a seguir.

(a) identificação: nome da SD, tempo de aplicação, público-alvo, conteúdo, objetivos (geral e específicos), os três momentos pedagógicos (problematização, organização e aplicação), e avaliação da aprendizagem, conforme o Quadro 1.

Quadrol. Formatação da Sequência Didática (SD) sobre Natureza da Ciência (NdC)

\begin{tabular}{|c|c|}
\hline \multicolumn{2}{|r|}{ SEQUÊNCIA DIDÁTICA (SD) SOBRE NATUREZA DA CIÊNCIA (NdC) } \\
\hline \multicolumn{2}{|r|}{ IDENTIFICAÇÃ0 } \\
\hline Nome da SD & Natureza da Ciência na formação inicial de professores \\
\hline Tempo de duração & 3 horas (180 minutos) \\
\hline Conteúdo & Natureza da Ciência: visões equivocadas de Ciência \\
\hline Público-alvo & Licenciandos \\
\hline \multirow[b]{2}{*}{ Objetivos } & $\begin{array}{l}\text { Geral: } \\
\text { - Compreender o conceito e as visões distorcidas de Ciência. }\end{array}$ \\
\hline & $\begin{array}{l}\text { Específicos: } \\
\text { - Conceituar Ciência; } \\
\text { - Identificar as visões equivocadas sobre Ciência. }\end{array}$ \\
\hline \multicolumn{2}{|r|}{ DESENVOLVIMENTO } \\
\hline \multicolumn{2}{|c|}{ Problematização inicial - Tempo estimado 40 minutos } \\
\hline \multicolumn{2}{|c|}{$\begin{array}{l}2^{\circ} \text { ) Em seguida, solicita que os alunos repassem a lista de palavras para outro aluno, que deve elaborar um } \\
\text { conceito de Ciência utilizando as palavras escritas por seu colega; } \\
3^{\circ} \text { ) Os conceitos elaborados serão discutidos com os participantes. Dessa forma, professores e alunos } \\
\text { conheceram as concepções de Ciência de cada participante. }\end{array}$} \\
\hline \multicolumn{2}{|c|}{ Organização do conhecimento - Tempo estimado 80 minutos } \\
\hline \multicolumn{2}{|c|}{$\begin{array}{l}\text { Agora, o professor utilizando material didático elaborado de acordo com as ideias dos autores que discutem } \\
\text { Natureza da Ciência (Durbano, 2015) e as visões equivocadas de Ciência (Cachapuz; et al, 2011), faz uma exposição } \\
\text { dialogada sobre os conteúdos: conceito de Ciência, importância da NdC no ensino e as concepçoes de Ciências. }\end{array}$} \\
\hline \multicolumn{2}{|c|}{ Aplicação do conhecimento - tempo estimado 60 minutos } \\
\hline \multicolumn{2}{|c|}{$\begin{array}{l}0 \text { docente formador propôs para os alunos analisarem uma situação-problema de sala de aula sobre a } \\
\text { concepção de Ciência de um docente. Discussão a partir das respostas e fechamento da SD. }\end{array}$} \\
\hline \multicolumn{2}{|l|}{ Avaliação } \\
\hline
\end{tabular}

Fonte: Elaborada pelos autores 
Formação Inicial de Professores de Biologia: Uma Proposta de Sequência Didática sobre a Natureza da Ciência

Problematização inicial - o professor deve apreender o conhecimento já construído pelo aluno, para aguçar as contradições e localizar as limitações desse conhecimento, quando cotejado com o conhecimento científico. A principal finalidade é problematizar o conhecimento que os estudantes vão expondo, de modo geral, com base em poucas questões propostas relativas à temática (DELIZOICOV; ANG0TTI; PERNAMBUCO, 2011). Assim, nesse momento de problematização inicial da SD, os procedimentos foram os seguintes:

a) 0 professor orientou cada participante escrever em uma folha 10 palavras que, na concepção deles, estariam relacionadas à Ciência.

b) Após a conclusão da relação de palavras, eles repassaram a sua lista de palavras para outro participante, que elaborou um conceito de Ciência de acordo com as palavras escritas pelo aluno anterior.

c) Em seguida, todos os participantes expuseram o conceito de Ciência elaborado a partir das palavras propostas pelo colega, que poderia concordar ou discordar da conceituação.

Organização do conhecimento - seleção dos conhecimentos necessários para a compreensão da temática abordada na problematização inicial; deve ser estudada sob a orientação do docente formador. As mais variadas atividades são empregadas, de modo que o professor possa desenvolver a conceituação identificada como fundamental para a compreensão científica da situação problematizadora (DELIZOICOV; ANGOTTI; PERNAMBUC0, 2011).

No segundo momento da SD, o professor utilizou textos elaborados de forma didática a partir dos autores Cachapuz, Gil-Perez, Carvalho e Vilches (2011) e Durbano (2015) sobre as temáticas "Natureza da Ciência e visões equivocadas da Ciência”, expondo os conceitos básicos para os alunos e confrontando com os conceitos atribuídos à Ciência na etapa anterior. Em seguida, desenvolvemos uma atividade que objetivou identificar as concepções de Ciência por meio das falas dos professores, ou seja, os licenciandos analisaram e identificaram as concepções equívocas de Ciência.

Aplicação do conhecimento - nesta fase, a meta foi capacitar os estudantes ao emprego dos conhecimentos, no intuito de formá-los para que articulem constante e rotineiramente a conceituação científica com situações reais, e não simplesmente encontrar uma solução. Seguindo o mesmo princípio do segundo momento, as atividades foram desenvolvidas buscando a generalização da conceituação que já foi abordada (DELIZOCOIV; ANGOTTI; PERNAMBUCO, 2011). No momento final, o docente formador propôs para os alunos a análise de uma situaçãoproblema de sala de aula, com o propósito de que reconhecessem a concepção de um docente. 


\section{Análise dos Dados}

Os dados foram examinados por um conjunto de técnicas de análise das comunicações, visando obter procedimentos sistemáticos e objetivos de descrição do conteúdo (atividades produzidas pelos participantes) e indicadores (quantitativos ou não) que permitiram a inferência de conhecimentos relativos às condições de produção/recepção dessas mensagens. Essas técnicas são denominadas Análise de Conteúdo (BARDIN, 2016). As categorias de análise que emergiram das atividades produzidas pelos participantes nos três momentos pedagógicos, foram:

1. Momento da problematização - palavras relacionadas à Ciência e ao conceito de Ciência - o conjunto de palavras associadas à Ciência foi reunido segundo a visão dos participantes.

2. Organização do conhecimento - concepções de Ciência - os conceitos de Ciência, segundo os participantes, foram identificados.

3. Aplicação do conhecimento - análise das visões de Ciência - incluir as respostas elaboradas pelos discentes aos questionamentos realizados sobre uma questão-problema.

\section{RESULTADOS E DISCUSSÃ0}

\section{Problematização Inicial}

Os resultados apresentados no quadro 2 foram obtidos a partir das respostas de uma atividade subdivida em duas etapas no momento de problematização inicial da SD, e teve como objetivo realizar um levantamento prévio sobre o conhecimento de Ciência dos alunos.

Quadro 2. Frequência das palavras associadas à Ciência

\begin{tabular}{|l|c|}
\hline Palavras & Frequência \\
\hline Ambiente, análise, aprimoramento, atualidade, autoconhecimento, & \\
habilidade, humano, informação, interagir, laboratório, bactérias, científico, \\
competências, comum, conscientização, contribuição, naturais, orientação, \\
plantas, políticas, prática, dedicação, diversidade, doenças, ecologia, ética, \\
exatas, filosofia, formação, qualidade, química, responsabilidade, resultados, \\
saneamento, seres vivos, teorias, higiene, habilidade.
\end{tabular}


Formação Inicial de Professores de Biologia: Uma Proposta de Sequência Didática sobre a Natureza da Ciência

\begin{tabular}{|l|c|}
\hline $\begin{array}{l}\text { Adaptação, informação, corpo, ensino, estudo, descobrimento } \\
\text { desenvolvimento. }\end{array}$ & 2 \\
\hline Avanço, evolução, biologia, natureza, sociedade. & 3 \\
\hline Conhecimento, tecnologia. & 4 \\
\hline Educação. & 6 \\
\hline Vida. & 7 \\
\hline Pesquisa. & 8 \\
\hline Saúde. & \\
\hline
\end{tabular}

Fonte: Elaborada pelos autores

Na primeira etapa da atividade, foi solicitado a cada aluno/a escrever 10 palavras que na concepção dele/a estariam associadas diretamente à Ciência. No quadro 2 podemos verificar que 57 palavras foram associadas à Ciência, sendo que 38 foram relacionadas com frequência (f) 01 e as palavras mais frequentes foram: educação $(\mathrm{f}=5)$; vida $(\mathrm{f}=6)$; pesquisa $(\mathrm{f}=7)$ e saúde $(\mathrm{f}=8)$. Analisamos que a maior frequência do vocabulário saúde, remete à percepção dos alunos que Ciência tem uma finalidade utilitária e que serve para o benefício do mundo que a cerca (SCHEID; BOER; OLIVEIRA, 2004).

Igualmente, podemos verificar que a maioria das palavras citadas estava associada às Ciências Biológicas. Por exemplo: plantas, natureza, evolução, naturais, seres vivos, vida, bactérias, entre outras. Consideramos que estes resultados apontam que estudantes de Ciências Biológicas, quando relacionam vocabulários para conceituar Ciência, limitam-se ao seu campo de conhecimento ou estudo (SCHEID; PERSICH; KRAUSE, 2009).

Na segunda etapa objetivou-se conceituar Ciência de acordo com as palavras associadas à Ciência. Dessa forma, os alunos elaboraram definições de Ciência de acordo com as palavras relacionadas por um dos colegas de sala de aula. Por exemplo: o aluno (Al) listou palavras e o aluno (A5) elaborou uma conceituação de Ciência a partir delas, conforme a Quadro 3.

Quadro 3. Definições de Ciências elaboradas pelos alunos a partir das palavras relacionadas

\begin{tabular}{|c|c|}
\hline Lista de Palavras & Definição de Ciência de acordo com as palavras \\
\hline $\begin{array}{l}\text { Natureza, saúde, avanço, } \\
\text { descobertas, humanas, exatas, vida, } \\
\text { pesquisa, atualidade e diversidade. Aluno } \\
\text { (Al) }\end{array}$ & $\begin{array}{l}\text { “Ciência é a que permiti [sic] pesquisar para que } \\
\text { possamos ter avanço para a saúde e a diversidade biológica } \\
\text { sejam preservados [sic] e as relações humanas, sejam } \\
\text { harmoniosas pelas descobertas da natureza que ajudam na } \\
\text { nossa saúde". Aluno (A5) }\end{array}$ \\
\hline
\end{tabular}




\begin{tabular}{|c|c|}
\hline $\begin{array}{l}\text { Higiene, bactérias, saúde, } \\
\text { sociedade, vida, doenças, saneamento, } \\
\text { cultura, educação, conscientização. Aluna } \\
\text { (A4) }\end{array}$ & $\begin{array}{l}\text { "[...] Ciência podemos acompanhar e compreender a } \\
\text { diversidade de áreas envolvidas, que vai [sic] desde o estudo } \\
\text { de seres microscópicos até meios que contribuem para } \\
\text { nossa qualidade de vida."Aluno (A9) }\end{array}$ \\
\hline $\begin{array}{l}\text { Transformação, vida, educação, } \\
\text { conhecimento, corpo humano, qualidade, } \\
\text { saúde, interagir, estudo, descobrimento. } \\
\text { Aluno (A8) }\end{array}$ & $\begin{array}{l}\text { ".../ Ciência é o estudo de vida onde podemos obter } \\
\text { conhecimento de qualidade para interagir sobre o corpo } \\
\text { humano ou outro descobrimento cientifico." Aluna (All) }\end{array}$ \\
\hline 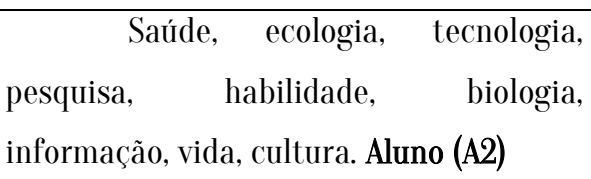 & $\begin{array}{l}\text { ".../ Ciência desempenha um papel de fundamental } \\
\text { importância propondo um conhecimento mais profundo. } \\
\text { Aluno (A6) }\end{array}$ \\
\hline
\end{tabular}

Fonte: Elaborada pelos autores

Os conceitos transcritos no quadro 3 foram importantes para discutir com o grupo as definições elaboradas. Ademais, evidenciamos que nesse grupo de graduandos há dificuldades de conceituar ciência, visto que, podemos verificar que as definições elaboradas não englobam os aspectos culturais, as normas da comunidade científica, as questões políticas que influenciam a ciência (DURBANO, 2015), além disso, os conceitos estão restritos as perspectivas utilitaristas relacionadas apenas as questões das Ciências Biológicas.

\section{Organização do Conhecimento}

Nesse momento, o professor explicou de forma expositiva a temática em discussão, com auxílio de materiais didáticos (textos e imagens). 0 objetivo nesta etapa foi expor os fundamentos básicos sobre a Natureza da Ciência (compreensão de Ciência como atividade humana, sobre o conceito de Ciência e as visões equivocadas). Também, ocorreu 0 desenvolvimento conceitual fundamental para o entendimento e compreensão científica (Cachapuz, et al, 2011).

Em seguida, os alunos realizaram uma atividade que teve a finalidade de analisar as falas de professores a respeito das suas concepções de Ciência. 0 quadro 4 reconhece as visões distorcidas da Ciência, a partir de falas de professores.

Quadro 4. Atividade proposta no segundo momento da SD

Atividade - Organização do conhecimento

Questão: Analise as falas dos professores identificados pelas letras A, B, C, D, E, F e G para reconhecer a visão que cada um apresenta sobre Ciência. 
Formação Inicial de Professores de Biologia: Uma Proposta de Sequência Didática sobre a Natureza da Ciência

\begin{tabular}{|c|c|c|}
\hline essor & Fala do professor sobre Ciência & $\begin{array}{l}\text { Visão de Ciência (respostas } \\
\text { dos alunos) }\end{array}$ \\
\hline A & $\begin{array}{l}\text { “Sim, tende a começar a partir da } \\
\text { observação que deve ser sistemática e controlada a } \\
\text { fim de que obtenha os fatos cientificos". (MOUSINH0; } \\
\text { SILVA; BRANDÃ0, 2016, p. 4). }\end{array}$ & $\begin{array}{l}\text { Resposta correta: visão } \\
\text { empírico-indutivista. } \\
09 \text { alunos conseguiram } \\
\text { reconhecer; } \\
02 \text { alunos não conseguiram } \\
\text { reconhecer. }\end{array}$ \\
\hline B & $\begin{array}{l}\text { "0 método científico é um aglomerado de } \\
\text { regras básicas de como deve ser o procedimento a } \\
\text { fim de produzir conhecimento científico". } \\
\text { (MOUSINHO; SILVA; BRANDÃo, 2016, p. 5). }\end{array}$ & $\begin{array}{l}\text { Resposta correta: visão rígida } \\
\text { infalível, exata. } \\
07 \quad \text { alunos conseguiram } \\
\text { reconhecer; } \\
04 \text { alunos não conseguiram } \\
\text { reconhecer. }\end{array}$ \\
\hline C & $\begin{array}{l}\text { "[...] os cientistas convivem com a natureza } \\
\text { observando as diferenças para torná-las em muitas } \\
\text { das vezes objetos de pesquisa.” (M0USINH0; SILVA; } \\
\text { BRANDÃ0, 2016, p. 5). }\end{array}$ & $\begin{array}{l}\text { Resposta correta: visão } \\
\text { aproblemática e ahistórica. } \\
08 \text { alunos conseguiram } \\
\text { reconhecer; } \\
03 \text { alunos não conseguiram. }\end{array}$ \\
\hline D & $\begin{array}{l}\text { "Cada uma compõe relações diferentes, a } \\
\text { biologia é relacionada aos organismos vivos, a física } \\
\text { incorpora o universo, e a química atômica e } \\
\text { molecular". (MOUSINH0; SILVA; BRANDÃ0, 2016, p. 6). }\end{array}$ & $\begin{array}{l}\text { Resposta correta: visão } \\
\text { analítica. } \\
06 \text { alunos conseguiram } \\
\text { reconhecer; } \\
\text { 05 alunos não conseguiram. }\end{array}$ \\
\hline E & $\begin{array}{l}\text { "Sim, a ciência sobrevive de descobertas } \\
\text { científicas e a soma de conhecimento é um trabalho } \\
\text { evolutivo do conhecimento". (MOUSINHO; SILVA; } \\
\text { BRANDÃO, 2016, p. 7). }\end{array}$ & $\begin{array}{l}\text { Resposta correta: visão } \\
\text { analítica. } \\
06 \text { alunos conseguiram } \\
\text { reconhecer; } \\
\text { 05 alunos não conseguiram. }\end{array}$ \\
\hline $\mathrm{F}$ & $\begin{array}{l}\text { "Somente um gênio tem um dom especial } \\
\text { para ser um cientista, por isso, se dedica muito aos } \\
\text { estudos científicos" (adaptada de MOUSINHO; SILVA; } \\
\text { BRANDÃO, 2016). }\end{array}$ & $\begin{array}{l}\text { Resposta } r \\
\text { individualista e elitista. } \\
08 \text { alunos } \text { conseguiram } \\
\text { reconhecer; } \\
03 \text { alunos não conseguiram. }\end{array}$ \\
\hline G & $\begin{array}{l}\text { "[...] a religião e a política não exercem } \\
\text { grande poder sobre a sociedade e consequentemente } \\
\text { influenciam no desenvolvimento da ciência" } \\
\text { (adaptada de MOUSINH0; SILVA; BRANDÃO, 2016). }\end{array}$ & $\begin{array}{l}\text { Resposta correta: socialmente } \\
\text { neutra. } \\
06 \quad \text { alunos conseguiram } \\
\text { reconhecer; } \\
05 \text { alunos não conseguiram. }\end{array}$ \\
\hline
\end{tabular}

Fonte: Elaborada pelos autores 
As respostas dos graduandos disponibilizadas na terceira coluna do quadro, sugerem que a aplicação da atividade de análise de falas dos professores adaptadas do trabalho de Mousinho; Silva; Brandão (2016) contribuiu para melhorar a compreensão deles sobre as visões equivocadas de Ciência apontadas por Cachapuz et al. (2011). Desse modo, os estudantes conseguiram reconhecer as visões distorcidas de Ciência, de acordo com as falas professores representados pelas letras A, B, C, D, E, F, G. Assim como o referido exercício proporcionou discussões com questionamentos durante a correção em sala de aula.

\section{Aplicação do Conhecimento}

Na aplicação, discussão e correção da atividade proposta anteriormente, os alunos puderam incorporar, compreender e interpretar melhor os conhecimentos apresentados no desenvolvimento da SD. Então, no momento da aplicação do conhecimento, objetivamos capacitar os futuros professores ao emprego dos conhecimentos científicos. Assim, propusemos uma atividade significativa que simulava um fato da profissão docente. Dessa forma, os estudantes foram estimulados a resolver a situação problema apresentada no Quadro 5.

Quadro 5. Situação-problema apresentada no terceiro momento pedagógico da SD

\section{SITUAÇÃO-PROBLEMA}

"João é um professor da rede estadual de ensino. Ele leciona o componente curricular de Ciências para as turmas do 6. - ano do Ensino Fundamental de uma escola localizada na zona urbana de uma cidade. O conteúdo que João está ministrando para uma das turmas é sobre as etapas do método científico. Durante a explicação do conteúdo, um aluno fez o seguinte questionamento: "professor, todos os cientistas têm de seguir esse método para fazer ciência?" Então, João respondeu: "claro que sim, pois se eles não seguirem o método haverá falha na sua pesquisa". Analise a situação acima e responda.

Fonte: Elaborado pelos autores

Os alunos dialogaram em dupla para resolver a situação proposta. Diante dessa atividade, obtivemos as seguintes respostas apresentadas no Quadro 5. 
Formação Inicial de Professores de Biologia: Uma Proposta de Sequência Didática sobre a Natureza da Ciência

Quadro 6. Respostas dos alunos

\begin{tabular}{|c|c|}
\hline $\begin{array}{l}\text { Situação problema } \\
\text { (perguntas) }\end{array}$ & Respostas dos alunos \\
\hline $\begin{array}{l}\text { Você considera que } \\
\text { a resposta que o professor } \\
\text { deu ao aluno está correta? }\end{array}$ & $\begin{array}{l}\text { "Não"(alunos: Al e A5) } \\
\text { "Não"(alunos: A8 e A10) } \\
\text { "Não" (alunos: A4 e A7) }\end{array}$ \\
\hline $\begin{array}{r}\text { Qual é a concepção } \\
\text { de Ciência do Professor João? }\end{array}$ & $\begin{array}{l}\text { "O professor tem uma concepção equivocada sobre a abrangência da } \\
\text { Ciência, que não se restringe apenas ao segmento de métodos". (alunos: Al e } \\
\text { A5). } \\
\text { "Por que cada etapa do método científico pode ser diferente e cada } \\
\text { cientista pode criar sua própria metodologia, pois a Ciência está em constante } \\
\text { transformação. O professor João acredita que a Ciência é imutável[...]" (alunos: } \\
\text { A8 e A10). } \\
\text { "[...] a concepção de Ciência do professor João é rígida e infalível". } \\
\text { (alunos: A4 e A7) }\end{array}$ \\
\hline $\begin{array}{l}\text { Se você fosse } \\
\text { professor(a) desse aluno, qual } \\
\text { seria a sua resposta para a } \\
\text { pergunta realizada por ele? }\end{array}$ & $\begin{array}{l}\text { “Como professor, diria que existe sim uma linha a ser seguida, mas } \\
\text { que devesse estar atento às constantes mudanças que ocorrem nessa área. } \\
\text { Portanto, podemos visar que a Ciência não se baseia só em métodos e sim em } \\
\text { pesquisa, sempre buscando novos conhecimentos, pois a cada dia a Ciência se } \\
\text { depara com novos acontecimentos”. (alunos: Al e A5). } \\
\text { "A resposta seria que a Ciência é influenciada por fatores políticos, } \\
\text { cultural e social e por isso tem-se a necessidade de adaptar a estratégia para } \\
\text { fazer a pesquisa que se deseja”. (alunos: A8 e Al0). } \\
\text { ".... sabemos que os fatores que vêm a influência na Ciência que seria } \\
\text { a politica, cultura e a sociedade no caso os valores sociais." (alunos: A4 e A7) }\end{array}$ \\
\hline
\end{tabular}

Fonte: Elaborada pelos autores

Segundo Cachapuz et al. (2011), essa concepção que associa Ciência a uma sequência de etapas que devem ser seguidas com exatidão é bastante frequente nos professores que ensinam ciências, desse modo, a situação problema aplicada na SD teve como objetivo proporcionar aos futuros professores a reflexão e análise de discursos imprecisos em aulas de ciências do ensino fundamental, e que contribuem para perpetuar uma concepção equivocada de Ciência, assim, as respostas dadas pelos graduandos sugerem que eles perceberam que a fala do professor da situação-problema estava incorreta, além disso, consideramos que esse tipo de atividade contribui para a compreensão dos graduandos sobre o fato de que as concepções prévias dos professores podem gerar conflitos e erros que dificultam o ensino das Ciências ( DURBAN0, 2015). 


\section{CONSIDERAÇÕES FINAIS}

A Sequência Didática (SD) que configura como um conjunto de atividades ordenadas, estruturadas e articuladas para a realização de objetivos educacionais, tem um princípio e um fim conhecidos, tanto pelos professores como pelos alunos (ZABALA, 2014).

Neste trabalho, objetivou-se desenvolver e aplicar uma proposta de SD destinada à formação inicial de professores de Ciências Biológicas, com a intenção de ensinar a Natureza da Ciência e suas visões distorcidas, já que o conteúdo expresso pelas Ciências é fruto dos processos humanos de conhecer, aprender e compreender 0 conhecimento. Dessa forma, o desenvolvimento de ideias, conceitos e teorias científicas são fundamentais para ensinar Ciências (ARCE; SILVA; VAROTTO, 2011).

Posto isso, apontamos algumas considerações sobre a SD: possibilitou identificar os conhecimentos prévios dos futuros professores sobre Ciência; sobre as situações-problemas que foram abordadas, as falas e cotidianos dos professores que proporcionaram diálogos, reflexões, escritas e a compreensão da Ciência em suas dimensões sociais, políticas e culturais, além disso, ensinar as visões equivocadas sobre Ciência na formação inicial de professores de Ciências contribuem, em certa medida, para melhoria do ensino das ciências.

Por fim, vale ressaltar que a elaboração e validação de SD na formação inicial de professores sobre as temáticas que envolvam conhecimento científico, história da ciência e as concepções de Ciência e/ou tecnologia devem ser objetos de estudos e pesquisas futuras.

\section{REFERÊNCIAS BIBLIOGRÁFICAS}

ARCE, A.; SILVA, D.; VAROTTO, M. Ensinando Ciências na Educação Infantil. Campinas: Alínea, 2011.

BARDIN, Laurence. Análise de Conteúdo. Tradução: Luís Augusto Pinheiro. São Paulo: Edições 70, 2016.

CACHUPAZ, A. et al. A necessária renovação do ensino das Ciências. 2. ' São Paulo: Cortez, 2011.

CARVALHO, Anna Maria Pessoa de. Formação de professores de ciências: duas epistemologias em debate. Enseñanza de las ciencias: revista de investigación y experiencias didácticas, n. Extra, p. 2784-2790, 2013.

CHIZZ0TTI, A. Pesquisa em Ciências Humanas e Sociais. São Paulo: Cortez, 2018.

DELIZOICOV, D.; ANGOTTI, J. A.; PERnAMBUCO, M. M. Ensino de Ciências: fundamentos e métodos. São Paulo: Cortez, 2011.

DUBARNO, J. P. A Natureza da Ciência no ensino: importância, pesquisa e introdução. Curitiba: Prismas, 2015.

GROTZER, Tina A.; MILLER, Rebecca B.; LINCOLN, Rebecca A. Perceptual, attentional, and cognitive heuristics that interact with the nature of science to complicate public understanding of science. In: Advances in Nature of Science Research. Springer, Dordrecht, 2012. p. $27-49$. 
Formação Inicial de Professores de Biologia: Uma Proposta de Sequência Didática sobre a Natureza da Ciência

LEDERMAN, N. G. Students and teachers conceptions of the nature of science: a review of the research. Journal of Research in Science Teaching, v. 29, n. 4, p. 331-359, 1992.

MOURA, B. A. 0 que é Natureza da Ciência e qual sua relação com a História e Filosofia da Ciência. Revista Brasileira de História da Ciência, v. 7, n. 1, p. 32-46, 2014.

MOUSINHO, S. P.; SILVA, M. B.; BRANDÃ0, A. G. A visão de Ciência de professores e estudantes de Araruna-PB. In: III Congresso Nacional de Educação. Natal-RN, 2016.

R0S, A. C. La elaboración y evaluación de modelos científicos escolares es una forma excelente de aprender sobre la naturaleza de la ciência. In:11 Idea Clave: el desarrollo de la compentencia cientifica. Graó, p. 105-126, 2012.

SÁNCHEZ, Adriana Castro; GÓMEZ, Ruby Ramírez. Enseñanza de las ciencias naturales para el desarrollo de competencias científicas. Amazonia investiga, v. 2, n. 3, p. 30-53, 2013.

SCHEID, N.; BOER, N.; OLIVEIRA, N. Percepções sobre Ciência, cientistas e formação de professores de Ciências. XII Simpósio Sul Brasileiro de Ensino de Ciências. Anais... Canoas, 2004. (CD-ROM).

SCHEID, N. M.; PERSICH, G. D.; KRAUSE, J. C. Concepção de Natureza da Ciência e a educação científica na formação inicial. Encontro Nacional de Pesquisas em Educação em Ciências. VII Enpec, Florianópolis, 2009.

TEIXEIRA, P. M. M. A educação científica sob a perspectiva da pedagogia histórico-crítica e do movimento CTS no ensino de Ciências. Ciência \& Educação, v. 9, n. 2, p. 177-190, 2003.

UNESC0. Ensino de Ciências: o futuro em risco. Unesco, 2005.

VÁSQUEZ-ALONSO, A. et al. Consensos sobre a natureza da Ciência: a Ciência e a tecnologia na sociedade. Química Nova, p. 34-50, 2007.

ZABALA, A. A prática educativa: como ensinar. Porto Alegre: Artmed, 2014. 